\title{
EDUGAÇ̃̃o EM ARTE, TECNOLOGIAS E PROCESSOS
}

Este Dossiê trata de projetos desenvolvidos por professores em que arte, tecnologia e estética formam o lócus de suas pesquisas, e contemplam uma diversidade de abordagens mostrando amplos e multifacetados caminhos ao discutir processos da educação em arte. Ao pensarmos tecnologia(s) na educação é relevante trazermos estas reflexões para nossos leitores.

Reinmann e Bekk discutem o fato de que, embora as tecnologias de mídia de ponta tenham entrado no ensino da arte na escola por volta de 2001, ainda há ceticismo sobre a integração do computador e da mídia digital nas aulas de arte, em detrimento ao desenho e pintura. As autoras discutem o projeto "MediaArt @ Edu" que envolve várias instituições na Alemanha em que trabaIham abordagens artísticas a tecnologia interativa com jovens de meios desfavorecidos e/ou desempregados como medidas integradoras para uma preparação profissional. Sosnowski, Peres de Miles e Biasuz analisam, sob uma perspectiva bakhtiniana, diálogos verbais e visuais produzidos e compartilhados entre alunos de licenciatura em artes visuais de dois países, Brasil e Estados Unidos. Discutem as múltiplas vozes emergindo na análise das videocartas, imagens e diálogos registrados nas interações no ambiente virtual de aprendizagem e a compreensão do conceito de enunciado em Bakhtin, de autoria colaborativa e dos processos de formação da subjetividade em uma perspectiva ético-estética. Sharma apresenta, através lentes híbridas entre a filosofia Vedanta e os conceitos de rizoma e assemblage em Deleuze e Guattari, uma análise da arte e da cultura visual para pensar o contexto contemporâneo das políticas educacionais na Índia. Refere a importância dessa metodologia de análise para que múltiplas vozes e experiências sejam respeitadas, especialmente quando lidas e analisadas em contextos globais. Eça discutir discursos curriculares de arte educação na Europa analisando: o Relatório europeu da Education, Audiovisual and Culture Executive Agency de 2009 e o Parecer do Conselho Nacional da Educação de Portugal, emitido em 2013 sobre a educação para as mídias. O cerne da discussão aponta para o crescente desinteresse pela educação crítica apelando para um discurso mais comprometido sobre o papel da arte educação no curriculo das escolas públicas do que para uma oferta educativa verdadeiramente democrática. Ballange- 
-Morris descreve o Octagon Newark Earthworks, que são elevações ou montes de terra construídos por motivos religioso e/ou científicos há milênios por povos indígenas americanos, localizados em Ohio, USA. O artigo é uma introdução a uma investigação sobre a possibilidade de desenhar um currículo interativo o qual, através de um jogo online, mostra como estes povos indígenas nominavam as constelações, diferentemente dos nomes gregos que são estudados na escola. Michel Fariña e Tas Maier discutem a formação ética através do cinema e da virtualidade. Propõe um debate moral contemporâneo ao questionar se o cinema pode realmente ajudar a conhecer mais e a viver melhor com o desejo. Apresenta uma metodologia para a leitura de filmes baseados no pensamento de $\mathrm{Ba}$ diou, Zizek, Agamben e Lacan, utilizando plataformas virtuais e redes sociais desenvolvida na UBA, Argentina. Daniel relata as mudanças no evoluir da comunidade afro-americana de Bronzeville, em Chicago, USA, e como a arte com base na comunidade pode funcionar como um bem de valor no reconhecimento e desenvolvimento de suas bases culturais. Discute o processo de gentrificação que ocorre nesta comunidade e sugere como a arte pode funcionar como agente de memória encorajando o processo reflexivo ao interagir cognitiva e emocionalmente com as leituras de arte de outras comunidades. Bastos e Hutzel relatam o projeto Art in the Market da cidade de Cincinatti, USA, em um ensaio visual que busca ilustrar um processo de arte e educação popular comunitária, apresentando as dimensões relevantes dessa ação em forma de pesquisa-ação participativa. Tecendo imagens e texto, apresentam os fundamentos teóricos desta práxis da criação em arte em conjunto com a comunidade. Sutters discute os programas de formação de professores em arte e a necessária adaptação aos avanços tecnológicos. Apresenta uma abordagem etnográfica para o trabalho de campo em que o mapeamento virtual foi utilizado para visualizar os dados recolhidos e permitir reflexões posteriores Através da cartografia crítica e apoiado em Michel de Certeau analisa os dados recolhidos durante o estudo e faz respectivas implicações para o campo da disciplina de arte. Areias e Castro discutem a articulação entre as tendências em arte contemporânea e as reais possibilidades na pedagogia do teatro, analisando a questão da tecnologia nas aulas de teatro do Brasil. Articula as ideias de Philip Auslander e Michael Anderson considerando as tecnologias nas aulas de teatro, em diálogo com o pesquisadores da arte educação brasileira.

Maria Cristina Villanova Biasuz e Katyuscia Sosnowski 